\title{
ANTIOKSIDAN EKSTRAK METANOL KULIT PETAI (Parkia speciosa Hassk) DENGAN METODE 2,2-diphenyl-1-picrylhidrazyl
}

\author{
Alfin Surya* $)^{1}$, Dwi Putri Rahayu ${ }^{1}$ \\ ${ }^{1}$ Program Studi D-3 Analis Kesehatan \\ Universitas Abdurrab Pekanbaru Jl. Riau Ujung No. 73 Pekanbaru \\ email : alfin.surya@univrab.ac.id
}

\begin{abstract}
Indonesia is the country with the most petai production in the Southeast Asia. In general, people consume petai only parts of the seeds, while the skin is not used and thrown away so that it only becomes waste. This waste causes environmental pollution and contributes to flooding. Petai skin (Parkia speciosa Hassk.) contains alkaloids, saponins, and flavonoids which can be used as antioxidant in counteracting free radicals. The aim of this study is to determine the antioxidant activity of the petai skin (Parkia speciosa Hassk.) methanol extract with maceration time for 72 hours. This research uses the 2,2-diphenyl-1-picrylhidrazyl (DPPH) method and ascorbic acid which already contains positively controlled antioxidant activity. From this research, $\mathrm{IC}_{50}$ values on petai skin were $13,4 \mu \mathrm{g} / \mathrm{mL}$ and $6,9504 \mu \mathrm{g} / \mathrm{mL} \mu \mathrm{g} / \mathrm{mL}$ on arcorbic acid as a positive control . From the $\mathrm{IC}_{50}$ value it is known that the methanol extract of petai skin containing strong antioxidants to fight free radicals.
\end{abstract}

Keywords: Antioxidant, Free radicals, DPPH

\begin{abstract}
ABSTRAK
Indonesia merupakan negara dengan produksi petai terbanyak di kawasan Asia Tenggara. Pada umumnya, masyarakat mengonsumsi petai hanya bagian bijinya saja, sedangkan bagian kulitnya tidak dimanfaatkan dan dibuang begitu saja sehingga menjadi limbah. Limbah ini menyebabkan pencemaran lingkungan dan turut memberi kontribusi pada banjir. Kulit petai (Parkia speciosa Hassk.) diduga memiliki kandungan senyawa alkaloid, saponin dan flavonoid yang dapat dimanfaatkan sebagai antioksidan dalam menangkal radikal bebas. Penelitian ini bertujuan untuk menentukan aktivitas antioksidan pada ekstrak metanol kulit petai (Parkia speciosa Hassk.) dengan waktu maserasi selama 72 jam. Penelitian ini menggunakan metode 2,2diphenyl-1-picrylhidrazyl (DPPH) dan asam askorbat yang sudah diketahui memiliki aktivitas antioksidan yang kuat sebagai kontrol positif. Dari penelitian tersebut didapatkan nilai $\mathrm{IC}_{50}$ pada kulit petai sebesar $13,4 \mu \mathrm{g} / \mathrm{mL}$ dan $6,9504 \mu \mathrm{g} / \mathrm{mL} \mu \mathrm{g} / \mathrm{mL}$ pada asam askorbat sebagai kontrol positif. Dari nilai $\mathrm{IC}_{50}$ yang didapat diketahui bahwa ekstrak metanol kulit petai memiliki aktivitas antioksidan yang kuat untuk melawan radikal bebas.
\end{abstract}

Kata kunci: Antioksidan, Radikal bebas, DPPH. 


\section{PENDAHULUAN}

Kulit petai (Parkia speciosa Hassk.) merupakan limbah organik yang banyak ditemukan berserakan di pasar tradisional. Pada umumnya, masyarakat mengonsumsi petai hanya bagian bijinya saja, karena kulit petai dianggap tidak memiliki manfaat dan tidak memberikan nilai ekonomis. Namun penelitian terhadap kulit petai telah dilakukan sebelumnya untuk dapat dimanfaatkan dalam kehidupan. Kulit petai memiliki potensi sebagai antibakteri terhadap Staphylococcus aureus dan Escherichia coli (Kurniawati, 2014). Ekstrak kulit petai mengandung senyawa alkaloid, saponin dan flavonoid yang mana senyawa-senyawa tersebut dapat dimanfaatkan sebagai antioksidan (Fajrin dan Susila, 2019).

Antioksidan merupakan komponen yang dapat mencegah sel atau molekul teroksidasi dengan cara mendonorkan elektron atau atom hidrogen pada radikal bebas. Radikal bebas adalah suatu senyawa atau molekul yang tidak stabil di dalam sel yang memiliki satu atau lebih elektron yang tidak berpasangan pada orbital luarnya. Adanya elektron yang tidak berpasangan menyebabkan elektron bersifat reaktif sehingga senyawa tersebut menyerang dan mengikat elektron molekul yang berada disekitarnya. Dampak reaktifitas senyawa radikal bebas dapat berupa kerusakan sel atau jaringan, penyakit degeneratif, hingga penyakit kanker (Winarsi, 2007).

Tubuh manusia memiliki sistem pertahanan endogen terhadap serangan radikal bebas terutama terjadi melalui peristiwa metabolisme sel normal dan peradangan. Jumlah radikal bebas dapat mengalami peningkatan yang diakibatkan oleh faktor stress, radiasi, asap rokok, dan polusi lingkungan menyebabkan sistem pertahanan tubuh yang ada tidak memadai, sehingga tubuh memerlukan tambahan antioksidan dari luar yang dapat melindungi dari serangan radikal bebas. Berdasarkan sumbernya, antioksidan dibagi menjadi dua kelompok yaitu antioksidan alami dan antioksidan sintetik. Penggunaan antioksidan sintetik seperti Butylated Hydroxytoluene (BHT), Butylated Hydroxyanisole (BHA), Tertier Butylated Hydroxyanisole (TBHQ) telah dilarang, karena dapat memberikan dampak negatif bagi kesehatan tubuh. Oleh karena itu, penggunaan antioksidan alami sebagai pengganti semakin diminati karena dipercaya lebih aman untuk kesehatan (Sari, 2017).

Berdasarkan uraian tersebut maka peneliti tertarik untuk melakukan studi tentang potensi antioksidan dari ekstrak metanol kulit petai (Parkia speciosa Hassk.) menggunakan metode 2,2diphenyl-1-picrylhidrazyl (DPPH).

\section{BAHAN DAN METODE}

\section{Bahan}

Sampel yang digunakan dalam penelitian ini adalah kulit petai yang didapat dari Pasar Tradisional Jalan Kayu Manis Pekanbaru. Bahan yang digunakan adalah metanol, asam askorbat, akuades, alumunium foil, metanol grade HPLC. Alat yang digunakan adalah neraca analitik dan microplate reader berthold model LB-941.

\section{Metode}

Uji aktivitas antioksidan dilakukan menggunakan microplate reader berthold dengan metode 2,2-diphenyl-1-picrylhidrazyl (DPPH) pada panjang gelombang $520 \mathrm{~nm}$. Sampel sebanyak $2 \mathrm{mg}$ dilarutkan dalam $2 \mathrm{ml}$ metanol sehingga konsentrasi sampel menjadi $1000 \mathrm{ppm}$. Baris A dimasukkan sampel sebanyak $100 \mu \mathrm{L}$ (plate terdiri dari baris A - H masing-masing berjumlah 12 sumur). Sebanyak $50 \mu \mathrm{L}$ metanol dimasukkan pada masing-masing sumur pada baris B - F. Baris A dipipet sebanyak $50 \mu \mathrm{L}$ dan dimasukkan ke baris B, baris B dipipet $50 \mu \mathrm{L}$ dimasukkan ke baris $\mathrm{C}$ dan dilakukan hal yang sama sampai baris $\mathrm{F}$, baris $\mathrm{F}$ dipipet $50 \mu \mathrm{L}$ lalu dibuang, sehingga didapatkan konsentrasi $1000 \mathrm{ppm}, 500 \mathrm{ppm}, 250 \mathrm{ppm}, 125 \mathrm{ppm}, 62,5 \mathrm{ppm}$ dan 31,25 ppm. Sedangkan khusus pada baris $\mathrm{G}-\mathrm{H}$ diisi dengan metanol $50 \mu \mathrm{L}$, khusus pada baris $\mathrm{H}$ diisi hanya sumur 1-6. Baris A - G ditambahkan DPPH sebanyak $80 \mu \mathrm{L}$ dengan konsentrasi 40 ppm, kemudian 
diinkubasi selama 30 menit. Aktivitas penangkapan radikal diukur sebagai penurunan absorbansi DPPH dengan microplate reader, sebagai pembanding yaitu asam askorbat dengan konsentrasi 50 ppm.

\section{ANALISIS DATA}

Persentase inhibisi $\left(\mathrm{IC}_{50}\right)$ ditentukan dengan menggunakan analisis dengan membuat kurva hubungan antara persen hambatan dengan konsentrasi.

Nilai \% inhibisi dihitung dengan rumus sebagai berikut:

$$
\% \text { inhibisi }=\frac{\text { A kontrol-A sampel }}{A \text { kontrol }} \times 100 \%
$$

Keterangan : $\quad \mathrm{A}_{\text {control }}=$ Absorbansi yang tidak mengandung sampel

$\mathrm{A}_{\text {sampel }}=$ Absorbansi yang mengandung sampel

Adapun rumus persamaan linier sebagai berikut:

Keterangan :

$$
y=a x+b
$$

$\mathrm{y}=$ Absorbansi sampel

$\mathrm{x}=$ Konsentrasi sampel

\section{HASIL DAN PEMBAHASAN}

\section{Hasil Uji Aktivitas Antioksidan}

Analisis aktivitas antioksidan ekstrak metanol kulit petai (Parkia speciosa Hassk.) menggunakan metode DPPH dengan microplate reader berthold model LB-941 pada panjang gelombang $520 \mathrm{~nm}$ menghasilkan nilai $\mathrm{IC}_{50}$ seperti yang terlihat pada tabel berikut:

Tabel I. \% Inhibisi ekstrak methanol kulit Petai

\begin{tabular}{ccc}
\hline $\begin{array}{c}\text { Konsentrasi metanol } \\
(\boldsymbol{\mu g} / \mathbf{m L})\end{array}$ & Ln konsentrasi $(\mathbf{X})$ & \% Hambatan $(\mathbf{Y})$ \\
\hline 1000 & 6,908 & 96,887 \\
500 & 6,215 & 90,532 \\
250 & 5,521 & 85,863 \\
125 & 4,828 & 78,47 \\
62,5 & 4,135 & 66,018 \\
31,25 & 3,442 & 57,977 \\
\hline
\end{tabular}

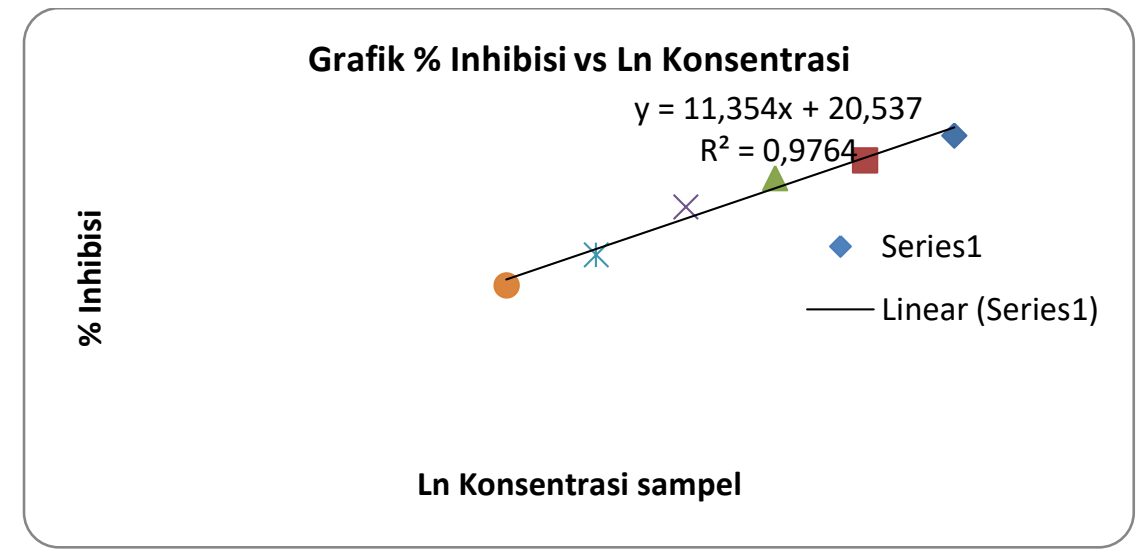


JOPS (Journal Of Pharmacy and Science)

Vol. 3, No.2, Bulan Juni 2020, Hal. 1-5

p-ISSN: 2622-9919; e-ISSN: 2615-1006

Perhitungan $\mathrm{IC}_{50}$

Gambar 1. Grafik hubungan persen inhibisi dan Ln konsentrasi

Persamaan regresi liniear :

$\mathrm{Y} \quad=11,354 \mathrm{X}+20,537$

$50=11,354 \operatorname{Ln} \mathrm{X}+20,537$

$\operatorname{LnX}=2,6$

$\mathrm{X}=13,4$

$\mathrm{IC}_{50}=13,4 \mu \mathrm{g} / \mathrm{mL}$

Sedangkan hasil aktivitas antioksidan asam askorbat sebagai kontrol positif adalah terlihat pada tabel berikut:

Tabel II. \% Inhibisi asam askorbat

\begin{tabular}{ccc}
\hline $\begin{array}{c}\text { Konsentrasi metanol } \\
(\boldsymbol{\mu g} / \mathbf{m L})\end{array}$ & Ln konsentrasi $(\mathbf{X})$ & \% Hambatan $(\mathrm{Y})$ \\
\hline 100 & 4,605 & 91,444 \\
50 & 3,912 & 81,711 \\
25 & 3,219 & 68,342 \\
12,5 & 2,526 & 57,326 \\
6,25 & 1,833 & 47,914 \\
3,125 & 1,138 & 39,358 \\
\hline
\end{tabular}

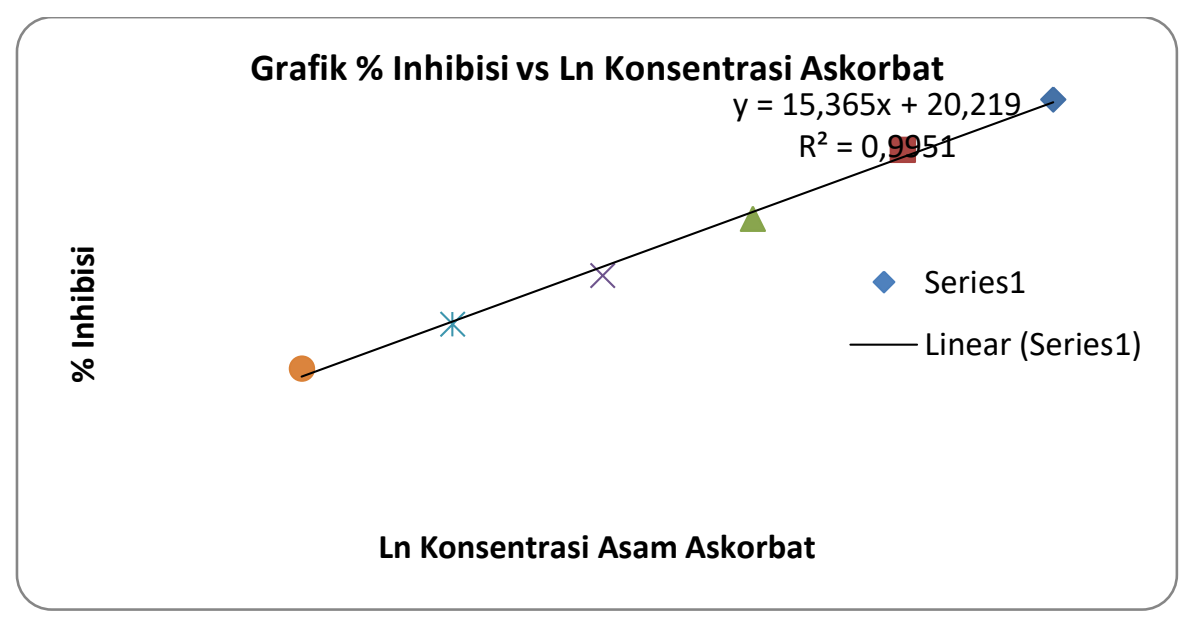

Gambar 2. Grafik hubungan persen inhibisi dan Ln konsentrasi askorbat

Perhitungan $\mathrm{IC}_{50}$ Asam Askorbat

Persamaan regresi liniear:

$\mathrm{Y}=15,36 \mathrm{X}+20,22$

$50=15,36 \mathrm{X}+20,22$

$\operatorname{LnX}=1,9388$

$\mathrm{X}=6,9504$

$\mathrm{IC}_{50}=6,9504 \mu \mathrm{g} / \mathrm{mL}$ 


\section{Pembahasan}

Prinsip dari uji ini adalah senyawa antioksidan akan bereaksi dengan radikal DPPH melalui mekanisme donasi atom hidrogen dan menyebabkan terjadinya perubahan warna DPPH dari ungu menjadi kuning yang diukur pada panjang gelombang serapan maksimum $520 \mathrm{~nm}$. Aktivitas antioksidan dilakukan menggunakan metode DPPH karena merupakan metode yang sederhana, mudah, cepat dan peka serta hanya memerlukan sedikit sampel (Moektiwardoyono, 2019). Metode ini menggunakan kontrol positif sebagai pembanding untuk mengetahui aktivitas antioksidan sampel. Pada penelitian ini menggunakan asam askorbat sebagai pembandingnya. Aktivitas antioksidan sampel ditentukan oleh besarnya daya hambat radikal DPPH melalui perhitungan persen inhibisi serapan DPPH. Kemudian dibuat kurva antara konsentrasi larutan sampel dengan persen inhibisi, sehingga diperoleh persamaan linearnya dan dapat dihitung nilai $\mathrm{IC}_{50}$.

Nilai IC $_{50}$ merupakan konsentrasi senyawa antioksidan yang memberikan inhibisi sebesar $50 \%$ yang artinya pada konsentrasi tersebut antioksidan dapat menghambat radikal bebas sebesar $50 \%$. Nilai $\mathrm{IC}_{50}$ berbanding terbalik dengan kapasitas antioksidan, artinya semakin kecil nilai $\mathrm{IC}_{50}$ maka semakin tinggi kapasitas antioksidan sampel tersebut (Susanto, 2019). Pada kontrol positif asam askorbat didapatkan nilai $\mathrm{IC}_{50}$ sebesar $6,9504 \mu \mathrm{g} / \mathrm{mL}$, aktivitas antioksidannya sangat kuat karena merupakan larutan yang sudah murni. Pada sampel ekstrak metanol kulit petai didapatkan nilai $\mathrm{IC}_{50}$ sebesar $13,4 \mu \mathrm{g} / \mathrm{mL}$ yang termasuk dalam kategori antioksidan yang kuat. Berdasarkan penelitian ini diketahui bahwa kulit petai sangat baik dimanfaatkan sebagai antioksidan untuk menangkal radikal bebas.

\section{KESIMPULAN}

Hasil analisis pengujian aktivitas antioksidan pada ekstrak metanol kulit petai menggunakan metode DPPH didapatkan nilai $\mathrm{IC}_{50}$ sebesar $13,4(\mu \mathrm{g} / \mathrm{mL})$. Hal ini menunjukkan bahwa esktrak metanol kulit petai memiliki aktivitas antioksidan yang kuat.

\section{UCAPAN TERIMAKASIH}

Peneliti mengucapkan terimakasih kepada kedua orang tua, dosen, dan teman-teman yang sudah memberikan bantuannya dalam menyelesaikan artikel ini.

\section{DAFTAR PUSTAKA}

Fajrin, F. I dan Susila, I. 2019. Uji Fitokimia Ekstrak Kulit Petai Menggunakan Metode Maserasi. Prosiding Seminar Nasional Teknologi dan Sains. Hal. 455 - 462.

Kurniawati, A. D. 2014. Aktivitas Antibakteri Ekstrak Kulit Petai (Parkia speciosa Hassk.) Terhadap Bakteri Escherichia coli dan Staphylococcus aureus. Skripsi. Program Sarjana Institut Pertanian Bogor. Bogor.

Moektiwardoyono, M. 2019. Jawer Kotok, Plectranthus Scutellariodies, dari Etnofarmasi Menjadi Sediaan Fitofarmasi. Deepublish. Yogyakarta.

Sari, A. N. 2017. Potensi Antioksidan Alami Pada Ekstrak Daun Jamblang (Syzigium cumini (L.) Skeels). Eksakta: Berkala Ilmiah Bidang MIPA. Volume 18 (2): Halaman 107 - 112.

Susanto, E. 2019. Peptida Bioaktif Sebagai Antioksidan Eksplorasi Pada Ceker Ayam. Deepublish. Yogyakarta.

Winarsi, H. 2007. Antioksidan Alami dan Radikal Bebas. Cetakan ke-1. Kanisius. Yogyakarta. 